\title{
Untangling the Intracellular Mechanisms Underlying Toxicity of Drugs of Abuse: A Review of the Detrimental Effects of New Psychoactive Substances (NPS)
}

\section{Diana Dias da Silva*}

Biological Sciences Department, University of Porto, Portugal

Submission: March 10, 2018; Published: April 23, 2018

*Corresponding author: Diana Dias da Silva, REQUIMTE Laboratory of Toxicology, Biological Sciences Department, Faculty of Pharmacy, University of Porto, Portugal, Email: diana.dds@gmail.com

\section{Mini Review}

The recreational drug world is continuously evolving. Of note, the number of new psychoactive substances (NPS) reported for the first time has spread year on year. In 2016, 66 NPS were notified to the European early-warning system [1], reflecting the fast pace at which new drugs are introduced onto the market (over one per week). By the end of 2016, the European authorities were monitoring more than 620 NPS, compared with 350 in 2013 [1]. This fast-paced surge embodies a major challenge for (inter)national policy-makers due to the inefficient monitoring techniques, relevant social and lifethreatening impact, and inadequate response by health care providers.

NPS are mainly of synthetic origin and comprise distinct drug classes, cannabinoids, cathinones, piperazines, benzofurans, and opioids, being the most prevalent [1-14]. Many NPS are analogues of existing controlled drugs or pharmaceuticals initially developed as pharmacological research tools or potential therapeutic agents; but often designer molecules displaying completely distinct structures have also emerged [117]. Most NPS are often used in combination $[1,3-6,8,9,12,13,15-$ 18]. Although NPS are intended to mimic psychoactive effects of classic drugs (ecstasy, cannabis, heroin, etc.), they pose especially serious concerns for public health as they are endowed with noticeably higher potency. Clinical signs of intoxication are consistent with the pharmacological mechanisms of the corresponding classic congeners, but often NPS more strongly bind and activate biological targets, widening the severity and assortment of deleterious effects $[1,3,4,6,8,9,11-13,15-17]$.

Figure 1: Schematic representation of putative intracellular mechanistic pathways sparked by New Psychoactive Substances (NPS). 
While the number of NPS-related poisonings and deaths peaked at unparalleled alarming levels [1,3,9,11-13,15-17], scarce information is available on toxicological mechanisms and toxicokinetic profiles of most novel drugs. Recent in vitro works have shed some light on the molecular pathways implicit in NPS detrimental effects, for which much contributed my team's work over the last years [19-27]. Our research provided compelling evidence that a plethora of NPS related to piperazine $[20,21,23-25,27]$, cathinone $[19,22,26]$ and benzofuran [22] disrupt oxidative and energetic intracellular homeostasis and mitochondrial functioning, culminating on the activation of cell death pathways (Figure 1). Studies on the metabolism of some NPS displaying a methylenedioxy ring revealed analogies to those of respective classic drugs, implicating metabolic bioactivation as a source of ROS and other reactive compounds, including metabolites that exhibit higher toxicity than the parent drug [28]. Related toxicity mechanisms are therefore putatively expected for those NPS exhibiting similar structural backbones.

In agreement with several reports of clinical complications following co-abuse of NPS [4-6,8,9,13,15-18], another relevant toxicokinetic expectation stems from the occurrence of drugdrug interactions, as several classic drugs [29-35] and some NPS $[19,23,24]$ have already proved to drastically exacerbate each others' toxicity when combined, even at non-toxic single doses.

A few years ago, most readily accessible information regarding the effects of NPS was originated from anecdotal reports from users posted to web-based drug discussion forums, and from clinical and forensic reports of deaths or severe injury. In spite of the significant recent advances on knowledge to the field, the toxicological profile of the majority of NPS remains far from being fully elucidated and studies are constantly required to assist interventions by law enforcement authorities, forensic laboratories, and medical providers. In this line, novel information on NPS pharmacokinetic properties and detection methods is imperative for the early detection of these drugs, clinical diagnosis of their intoxications, as well as to obtain and interpret forensic results. Also, the disclosure of the toxicological mechanisms involved in the detrimental NPS effects might provide relevant insights into the reasons behind occurrence of such extreme toxicity, potentiating the identification of therapeutic targets. All together, these aspects may embody an outstanding social impact by allowing estimations on the risk of drug threats, devising plans for minimizing such risks, and influencing (inter)national drug prevention policies.

Common mechanisms of cytotoxicity for synthetic amphetamines, cannabinoids, cathinones, piperazines, benzofurans, and opioids include pro-oxidative burst, with increased generation of reactive oxygen and nitrogen species (ROS/RNS), depletion of reduced glutathione (GSH) and concurrent formation of glutathione disulfide (GSSG). Oxidative stress is associated with abnormal function of intracellular organelles, such as the Endoplasmic Reticulum (ER), mitochondria, and lysosome. Disruption of mitochondrial functioning is accompanied by dissipation of mitochondrial membrane potential $(\Delta \Psi \mathrm{m})$ and depletion of energetic stores (ATP). Since both the ER and mitochondria play vital roles in the homeostasis of intracellular $\mathrm{Ca}^{2+}$, mitochondrial and ER stress induced by ROS/RNS overload may result in $\mathrm{Ca}^{2+}$ dumping from these organelles into the cytoplasm, impelling activation of intracellular signaling pathways that evolve to cell death. Lysosomal impairment, by turn, may result in accumulation of material taken up from outside the cell to be digested or obsolete components of the cell itself, which may eventually affect the overall cell functioning and also culminate in cell death. All together, these mechanisms compel cell to suicide, as evidenced by chromatin condensation, pyknotic nuclei, and activation of both extrinsic (cleavage of caspase 8) and intrinsic (cleavage of caspase 9) apoptotic pathways that ultimately converge in activation of the execution phase (demonstrated by cleavage of caspase 3). Also of relevance, the interaction of NPS with the cytochrome P450 metabolizing enzymes may represent serious clinical consequences, as NPS are often co-consumed with other drugs. Accordingly, the inhibition of several isoforms had already proven to alter the toxicity of these drugs.

\section{References}

1. European Drug Report 2017, European Monitoring Centre for Drugs and Drug Addiction (EMCDDA).

2. Maciów-Głąb M, Kula K, Kłys M, Rojek SD (2017) New psychoactive substances in substantive evidence in expert practice of the Department of Forensic Medicine, UJCM in the years 2010-2015. Arch Med Sadowej Kryminol 67(3): 178-200.

3. World Drug Report 2017 United Nations Office on Drugs and Crime (UNODC).

4. Barcelo B, Gomila I, Rotolo MC, Marchei E, Kyriakou C, et al. (2017) Intoxication caused by new psychostimulants: analytical methods to disclose acute and chronic use of benzofurans and ethylphenidate. Int J Legal Med 131(6): 1543-1553.

5. Palamar JJ, Salomone A, Gerace E, Di Corcia D, Vincenti M et al. (2017) Hair testing to assess both known and unknown use of drugs amongst ecstasy users in the electronic dance music scene. Int J Drug Policy 48: 91-98.

6. Staeheli SN, Boxler MI, Oestreich A, Marti M, Gascho D et al. (2017) Postmortem distribution and redistribution of MDAI and 2-MAPB in blood and alternative matrices. Forensic Sci Int 279: 83-87.

7. Liu C, Li T, Han Y, Hua Z, Jia W, et al. (2017) The identification and analytical characterization of 2,2'-difluorofentanyl. Drug Test Anal 10(4): 774-780.

8. Brandehoff N, Adams A, McDaniel K, Banister SD, Gerona R, et al. (2018) Synthetic cannabinoid "Black Mamba" infidelity in patients presenting for emergency stabilization in Colorado: a P SCAN Cohort. Clin Toxicol (Phila) 56(3): 193-198.

9. Beck O, Bäckberg M3, Signell P2, Helander A (2018) Intoxications in the STRIDA project involving a panorama of psychostimulant pyrovalerone derivatives, MDPV copycats. Clin Toxicol (Phila) 56(4): 256-263.

10. Lehmann S, Kieliba T, Beike J, Thevis M, Mercer-Chalmers-Bender K (2017) Determination of 74 new psychoactive substances in serum using automated in-line solid-phase extraction-liquid chromatographytandem mass spectrometry. J Chromatogr B Analyt Technol Biomed Life Sci 1064: 124-138. 
11. Allibe N, Richeval C, Phanithavong M, Faure A, Allorge D, et al. (2017) Fatality involving ocfentanil documented by identification of metabolites. Drug Test Anal.

12. Krotulski AJ, Papsun DM, Friscia M, Swartz JL, Holsey BD, et al. (2017) Fatality Following Ingestion of Tetrahydrofuranylfentanyl, U-49900 and Methoxy-Phencyclidine. J Anal Toxicol p. 1-6.

13. Rojek S, Korczyńska-Albert M, Kulikowska J, Kłys M (2017) New challenges in toxicology of new psychoactive substances exemplified by fatal cases after UR-144 and UR-144 with pentedrone administration determined by LC-ESI-MS-MS in blood samples. Arch Med Sadowej Kryminol 67(2): 104-120.

14. Bertol E, Bigagli L, D’Errico S, Mari F, Palumbo D, et al. (2018) Analysis of illicit drugs seized in the Province of Florence from 2006 to 2016 Forensic Sci Int 284: 194-203.

15. Ellefsen KN, Taylor EA, Simmons P, Willoughby V, Hall BJ (2017) Multiple Drug-Toxicity Involving Novel Psychoactive Substances, 3-Fluorophenmetrazine and U-47700. J Anal Toxicol 41(9): 765-770.

16. Loi B, Corkery JM, Claridge H, Goodair C, Chiappini S, et al. (2015) Deaths of individuals aged 16-24 years in the UK after using mephedrone. Hum Psychopharmacol 30(4): 225-232.

17. Tait RJ, Caldicott D, Mountain D, Hill SL, Lenton S (2016) A systematic review of adverse events arising from the use of synthetic cannabinoids and their associated treatment. Clin Toxicol (Phila) 54(1): 1-13.

18. Fernandez Calderon F, CM Cleland, JJ Palamar (2018) Polysubstance use profiles among electronic dance music party attendees in New York City and their relation to use of new psychoactive substances. Addict Behav 78: 85-93.

19. Araujo AM, Valente MJ, Carvalho M, Dias da Silva D, Gaspar H, et al. (2015) Raising awareness of new psychoactive substances: chemical analysis and in vitro toxicity screening of 'legal high' packages containing synthetic cathinones. Arch Toxicol 89(5): 757-771.

20. Arbo MD, Silva R, Barbosa DJ, da Silva DD, Rossato LG, et al. (2014) Piperazine designer drugs induce toxicity in cardiomyoblast h9c2 cells through mitochondrial impairment. Toxicol Lett 229(1): 178-189.

21. Arbo MD, Silva R, Barbosa DJ, Dias da Silva D, Silva SP, et al. (2016) In vitro neurotoxicity evaluation of piperazine designer drugs in differentiated human neuroblastoma SH-SY5Y cells. J Appl Toxicol 36(1): 121-130

22. Bravo R (2016) In Vitro Hepatotoxicity of Synthetic Cathinones and Benzofurans Used as Legal Highs, University of Porto: Portugal.

23. Dias da Silva D, et al. (2016) In vitro neurotoxicity of 'Legal X': The combination of 1-benzylpiperazine (BZP) and 1-(m-trifluoromethylphenyl)piperazine (TFMPP) induces mitochondrial impairment and disrupts thiol homeostasis in dopaminergic SH-SY5Y cells. Toxicology Letters 258: S247.

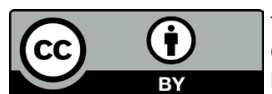

This work is licensed under Creative Commons Attribution 4.0 License DOI: 10.19080/OAJT.2018.03.555604
24. Dias da Silva D, et al. (2017) In vitro hepatotoxicity of 'Legal X': the combination of 1-benzylpiperazine (BZP) and 1-(m-trifluoromethylphenyl)piperazine (TFMPP) triggers oxidative stress, mitochondrial impairment and apoptosis. Arch Toxicol 91(3): 1413-1430.

25. Dias da Silva D, Arbo MD, Valente MJ, Bastos ML, Carmo H et al. (2015) Hepatotoxicity of piperazine designer drugs: Comparison of different in vitro models. Toxicol In Vitro 29(5): 987-996.

26. Ferreira B (2018) Evaluation of the influence of the metabolism on the cytotoxicity of 3-methylmethcathinone (3-MMC), University of Porto, Portugal.

27. Moreira P, Cunha S, Dias Da Silva D, Carvalho F, Bastos M, et al. (2016) Development and validation of a method for the simultaneous quantification of two piperazines used as drugs of abuse. Toxicology Letters 258: S296.

28. Valente MJ, Guedes de Pinho P, de Lourdes Bastos M, Carvalho F, Carvalho M (2014) Khat and synthetic cathinones: a review. Arch Toxicol 88(1): 15-45.

29. da Silva DD, E Silva, H Carmo (2014) Combination effects of amphetamines under hyperthermia - the role played by oxidative stress. J Appl Toxicol 34(6): 637-650.

30. da Silva DD, Silva E, Carvalho F, Carmo H (2014) Mixtures of 3,4-methylenedioxymethamphetamine (ecstasy) and its major human metabolites act additively to induce significant toxicity to liver cells when combined at low, non-cytotoxic concentrations. J Appl Toxicol 34(6): 618-627.

31. Dias da Silva D, Carmo H, Lynch A, Silva E (2013) An insight into the hepatocellular death induced by amphetamines, individually and in combination: the involvement of necrosis and apoptosis. Arch Toxicol 87(12): 2165-2185.

32. Dias da Silva D, H Carmo, E Silva (2013) The risky cocktail: what combination effects can we expect between ecstasy and other amphetamines? Arch Toxicol 87(1): 111-122.

33. Dias da Silva D, E Silva, H Carmo (2013) Cytotoxic effects of amphetamine mixtures in primary hepatocytes are severely aggravated under hyperthermic conditions. Toxicol In Vitro 27(6): 1670-1678.

34. Martins MJ, A Pinto, RR Bravo, H Carmo, F Carvalho, et al. (2016) Cocaine combined with heroin/morphine or ethanol disrupts mitochondrial and oxidative homeostasis. Toxicology Letters 258: S238.

35. Martins MJ, Patrícia Moreira, Maria João Martins, Diana Dias da Silva Félix Carvalho, et al. (2017) Oxidative damage and energetic crisis in cardiomyocites after co-exposure of cocaine and morphine. Toxicology Letters 280: S161.

\section{Your next submission with Juniper Publishers} will reach you the below assets

- Quality Editorial service

- Swift Peer Review

- Reprints availability

- E-prints Service

- Manuscript Podcast for convenient understanding

- Global attainment for your research

- Manuscript accessibility in different formats

( Pdf, E-pub, Full Text, Audio)

- Unceasing customer service

Track the below URL for one-step submission https://juniperpublishers.com/online-submission.php 